\title{
Expression of E-cadherin, $\alpha$-catenin, and $\beta$-catenin in the process of lymph node metastasis in oral squamous cell carcinoma
}

\author{
N Tanaka*,', T Odajima ${ }^{2}, K$ Ogi', T Ikeda ${ }^{2}$ and M Satoh ${ }^{2}$ \\ 'Department of Oral Surgery, Sapporo Medical University School of Medicine, South I, West 16, Chuou-ku Sapporo 060-006I Japan; ${ }^{2}$ Department of \\ Clinical Pathology, Sapporo Medical University Hospital, South I, West 16, Chuou-ku Sapporo 060-006I Japan
}

\begin{abstract}
Regional lymph node metastasis is a very important prognostic indicator. In the metastatic process, reduction in cell to cell adhesion including E-cadherin-catenin cell adhesion complex is an essential step. We investigated immunohistochemical expression of Ecadherin, $\alpha$-catenin and $\beta$-catenin in 159 tissue samples from patients with oral squamous cell carcinoma and examined the correlation between their expressions and the presence of regional lymph node metastasis. Significantly greater reduction in expression levels of E-cadherin, $\alpha$-catenin and $\beta$-catenin was found in the metastatic group $(n=64)$ compared to the nonmetastatic group $(n=95)(P=0.007,0.00 \mathrm{I}, 0.00 \mathrm{I}$, respectively). However, there was no significant correlation between their expressions and the features of the regional metastasis, the number of metastatic lymph nodes or the presence of extracapsular metastasis. These data suggest that evaluation of the immunohistochemical expression of E-cadherin, $\alpha$-catenin and $\beta$-catenin is extremely valuable for the diagnosis of metastatic occurrence.

British Journal of Cancer (2003) 89, 557-563. doi: I0.1038/sj.bjc.660II 24 www.bjcancer.com

(C) 2003 Cancer Research UK
\end{abstract}

Keywords: E-cadherin; $\alpha$-catenin; $\beta$-catenin; oral squamous cell carcinoma; metastasis

Among oral malignancies, squamous cell carcinoma is the most frequent and a number of studies have been conducted on the relationship between its clinical and pathological findings in order to improve the accuracy of prognosis for patients with this disease. We have already reported that a significantly reduced 5-year cumulative survival rate was observed in patients with oral squamous cell carcinoma and lymph node metastasis as compared with those without metastasis (Tanaka et al, 2001) and Jones et al (1993) also emphasised that lymph node metastasis is the most important prognostic indicator. As regards therapy, it is thus extremely important to identify the tumours that are likely to develop lymph node metastasis.

For metastasis to occur, cancer cells have to detach from the primary lesion as an initial step. E-cadherin is a $\mathrm{Ca}^{2+}$-dependent intercellular adhesion molecule in epithelial cells, which play an important role in establishing and maintaining intercellular connections and morphogenesis (Takeichi, 1991). The cytoplasmic terminus of the E-cadherin molecule has been shown to be linked to the actin cytoskeleton via $\alpha$-catenin and $\beta$-catenin (McCrea et al, 1991; Ozawa and Kemler, 1992; Knusden et al, 1995), and Ecadherin is directly associated with $\beta$-catenin and indirectly linked via the $\alpha$-catenin $/ \beta$-catenin heterodimeric complex to $\alpha$-catenin (Alberle et al, 1994; Oyama et al, 1994; Stappert and Kemler, 1994). It is reported that downregulation of the $\alpha$-catenin, and $\beta$-catenin seems to be associated with dysfunction of E-cadherin-mediated cell adhesion and an increase in the metastatic potential of cancer cells (Kadowaki et al, 1994; Matsui et al, 1994; Ochiai et al, 1994; Pierceall et al, 1995; Rimm et al, 1995). Changes or alteration in the function and expression of the cell to cell adhesion molecule, E-

*Correspondence: Dr N Tanaka; E-mail: ntanaka@sapmed.ac.jp Revised 24 March 2003; accepted 7 May 2003 cadherin, $\alpha$-catenin and $\beta$-catenin, have been postulated to be an early event in the multiple process of tumour metastasis and an important factor in tumour progression (Birchmeier et al, 1993; Ponta et al, 1994). A variety of studies regarding the relationship between the expression of E-cadherin, $\alpha$-catenin, $\beta$-catenin and the existence of lymph node metastasis in human cancers have been performed and some authors found a significant correlation (Sato et al, 1999; Zheng et al, 1999), while others did not (Mattijssen et al, 1993; Andrews et al, 1997).

This study was performed to clarify whether the expression of Ecadherin, $\alpha$-catenin and $\beta$-catenin was correlated with the existence of lymph node metastasis in 159 patients with oral squamous cell carcinoma. To the best of our knowledge, this study is the first report that has examined the effect of altered expression of these proteins on regional metastasis in oral squamous cell carcinoma.

\section{MATERIALS AND METHODS}

\section{Samples}

We obtained 159 primary tumour samples, at the time of either biopsy for initial diagnosis or surgical resection, from 159 patients with oral squamous cell carcinoma consisting of 84 cases of carcinoma of the tongue, seven of the upper gingiva, 26 of the lower gingiva, 27 of the floor of the mouth, 13 of the buccal mucosa and two cases of carcinoma of the lip. The patients were treated at the Department of Oral Surgery, Sapporo Medical University School of Medicine. The treatment modality employed was surgery under snap-frozen section control or induction chemotherapy followed by definitive surgery. None of the samples examined was influenced by chemotherapeutic agents because in the cases in 
which such agents were used, the samples were obtained as biopsy before the chemotherapy. The age of the patients ranged from 26 to 85 years (average, 59.0 years). There were 55 male and 104 female patients. The grade of histological differentiation was determined following WHO 1997 criteria. The mode of invasion at the tumour-host borderline was classified into three types (expansive, moderately invasive and markedly invasive), with a modification of criteria used by Umeda et al (1992). Briefly, the expansive type had a well-defined borderline, the moderately invasive type exhibited no distinct borderline and had parenchyma consisting of large tumour cell nests and the markedly invasive type spread in small aggregates with ramifications or invaded diffusely without forming nests of tumour cells. We divided the samples into two groups: (1) $\mathrm{pN}(-)$ group $(n=95)$ : cervical lymph node metastasis was not recognised clinicopathologically for at least 2 years after surgery, $(2) \mathrm{pN}(+)$ group $(n=64)$ : cervical lymph node was recognised. Among the $\mathrm{pN}(+)$ group, radical neck dissection was performed in 30 cases, functional neck dissection in 22 cases and supraomohyoid neck dissection was performed in 12 cases.

\section{Immunohistochemistry}

The tissue samples obtained were fixed in $10 \%$ buffered formalin and embedded in paraffin. Paraffin sections $(6 \mu \mathrm{m})$ were made, dewaxed, hydrated and immersed in citrate buffer $(0.001 \mathrm{M}$ citric acid, $\mathrm{pH}$ 6.0) for $5 \mathrm{~min}$ in an autoclave $\left(121^{\circ} \mathrm{C}\right)$ for antigen retrieval. The sections were rinsed with $0.001 \mathrm{~m}$ phosphate-buffered saline (PBS) three times for $5 \mathrm{~min}$ each time, and then immersed in $0.3 \%$ hydrogen peroxide containing methanol to inactive endogenous peroxidase, and to block for nonstaining in normal goat serum in PBS for $30 \mathrm{~min}$ at room temperature. The sections were then incubated with primary antibody (anti-E-cadherin dilution with $1: 100$ (clone 36, Transduction Laboratories, Kentucky, USA) anti- $\alpha$-catenin dilution with $1: 100$ (clone 5, Transduction Laboratories, Kentucky, USA) and anti- $\beta$-catenin dilution with $1: 100$ (clone 14, Transduction Laboratories, Kentucky, USA)) overnight at $4^{\circ} \mathrm{C}$, rinsed with $\mathrm{PBS}$ three times for $5 \mathrm{~min}$ each time, and incubated with the secondary antibody, biotinylated goat antimouse immunoglobulin (IgG) (SC-2039; Santa Cruz Biotechnology, Santa Cruz, CA) for $30 \mathrm{~min}$ at room temperature and then rinsed again as previously described. The sections were finally incubated in avidin-biotin complex (Vector Laboratories, Burlingame, CA, USA) for $60 \mathrm{~min}$ at room temperature, then rinsed again as previously described. Visualisation of the peroxidase was performed using diaminobenzine in PBS with $0.005 \%$ hydrogen peroxide for $5 \mathrm{~min}$. The sections were counterstained with haematoxylin, dehydrated and mounted. In each experiment, primary monoclonal antibodies were replaced with PBS in duplicate sections for negative controls.

\section{Evaluation of E-cadherin and catenins expression}

All sections were examined by three independent pathologists who were blinded to the patients' clinical information, using a slight modification of the scoring method described previously (Andrews et al, 1997), and the staining pattern was evaluated semiquantitatively by comparing the intensity and cellular localisation of immunostaining with those of the adjacent normal epithelium as an internal positive control. If immunoreaction was uniformly membraneous and strong, similar to that in the internal controls, the staining was defined as normal. When immunoreaction was negative or weak, with either heterogeneous (mixed areas of positive and negative cells with normal membraneous staining) and/or altered cellular distribution (cytoplasmic and/or nuclear staining in more than $20 \%$ of the tumour cells, regardless of membraneous staining) of immunostaining, the staining was classified as abnormal. For each molecule, levels of immunoreaction were graded according to whether more than $75,25-75$ or less

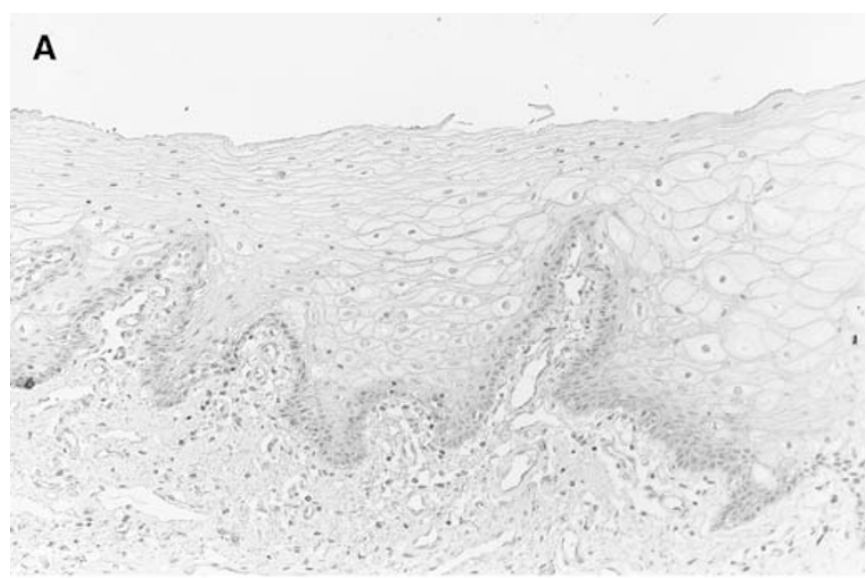

B

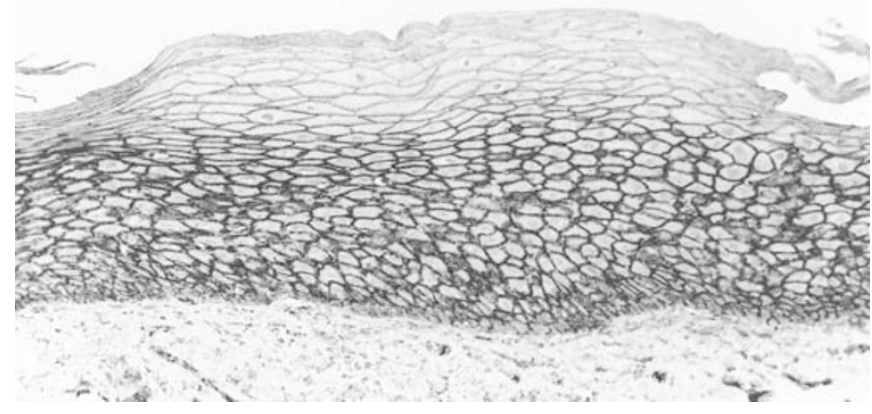

Figure I E-cadherin expression in normal oral epithelium. (A) Negative control, original magnification $\times 170$; $(\mathbf{B})$ E-cadherin is detected mainly on the cell membrane of the basal layer to the spinosum layer, original magnification $\times 170$

than $25 \%$ of cells showed the normal pattern of strong membraneous staining. For practical and statistical purposes, the immunoreactions in more than $75 \%$ and in less than $75 \%$ were also estimated as preserved and reduced, respectively. In tumours showing heterogeneity of staining, the immunostaining of the tumour was judged according to the prominent pattern. For each section, at least 500 cells, and usually more than 1000 tumour cells were analysed in 10 random high power fields $(\times 400)$. Whenever there were some discrepancies in the evaluation between observers, a consensus was reached using a multiheaded microscope. Cases in which internal positive control failed to show clear staining were excluded from this study.

\section{Statistical analysis}

All statistical analyses were performed using SPSS 10.0 J for Windows. The association between the presence of regional metastasis and clinicopathological variables was analysed using $\chi^{2}$ tests and Fishers exact tests. $P$-values $<0.05$ were considered to be statistically significant. Differences in survival analysed by the Kaplan-Meier method were assessed by the log-rank test.

\section{RESULTS}

Cytomembraneous expressions of E-cadherin, $\alpha$-catenin and $\beta$ catenin were observed from the basal layer to the spinosum layer of normal oral epithelia and lost in the superficial layer (Figure 1). 

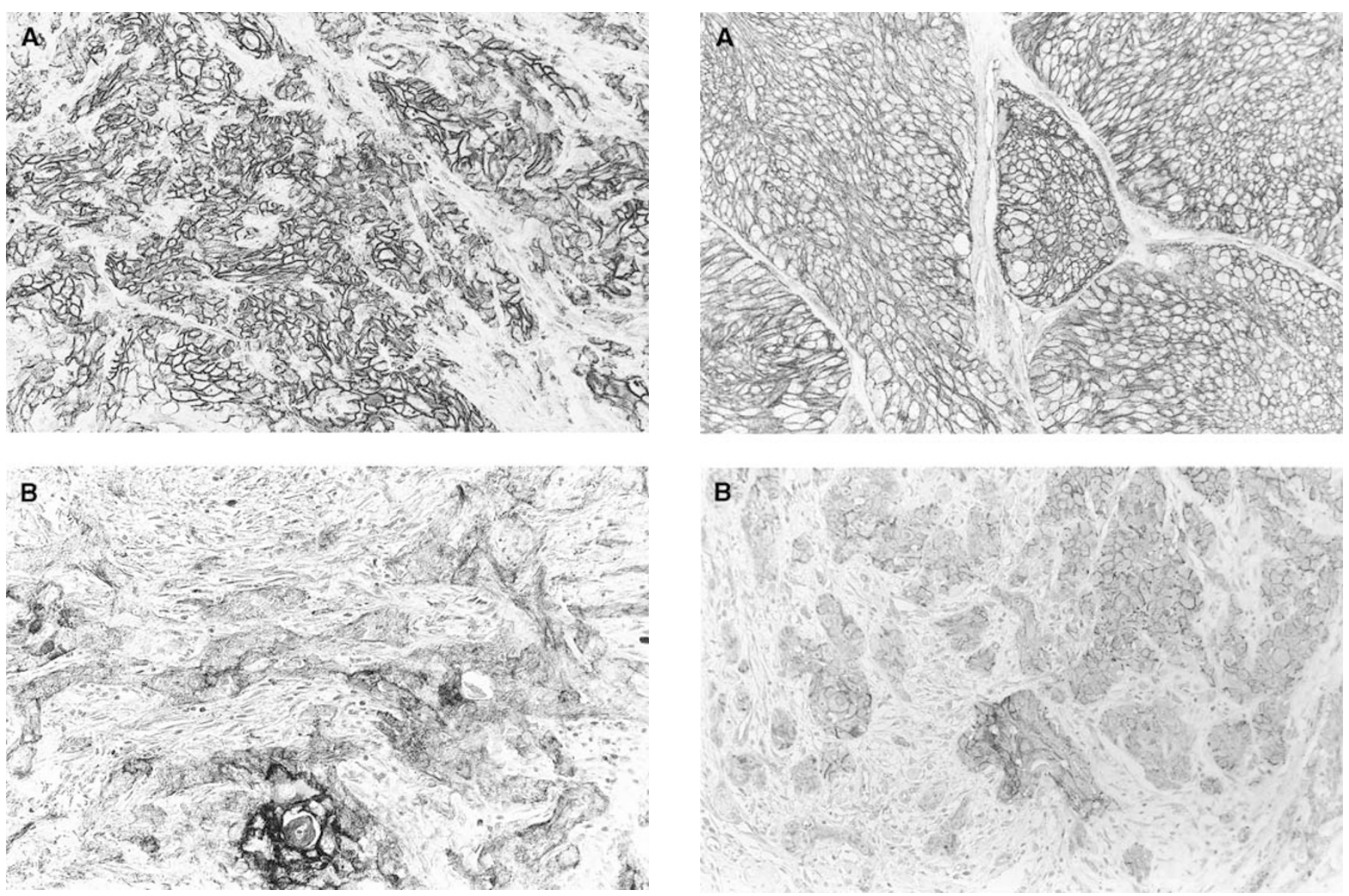

Figure 2 E-cadherin expression in oral squamous cell carcinoma. (A) An oral squamous cell carcinoma shows preserved E-cadherin expression, original magnification $\times$ 170; (B) An oral squamous cell carcinoma shows reduced E-cadherin expression, original magnification $\times 170$.

In the cancer cells, the expression was detected only in the cytomembrane, or both in the cytoplasm and the nucleus. Representative immunohistochemical stainings of these molecules are shown in Figures 2-4.

The expressions of E-cadherin, $\alpha$-catenin and $\beta$-catenin are summarised in Table 1. Out of the total 159 cases, reduced expression of E-cadherin, $\alpha$-catenin and $\beta$-catenin was found in 92 (57.9\%), $115(72.3 \%)$ and $114(71.7 \%)$, respectively.

\section{Association between expression of E-cadherin, $\alpha$-catenin, and $\beta$-catenin and existence of lymph node metastasis (Table 1)}

There was no significant association between age, gender, site of tumour or histological differentiation and the existence of lymph node metastasis in patients with oral squamous cell carcinoma.

Lymph node metastasis was found more frequently in the cases with T3 or T4 tumour than in those with T1 or T2 tumour $(P=0.001)$, and there was a significant association between a high grade of mode of carcinoma invasion of primary tumours and lymph node metastasis $(P=0.004)$.

Reduced E-cadherin expression was observed in 48 out of the 95 $\mathrm{pN}(-)$ cases, while it was seen in 44 out of the $64 \mathrm{pN}(+)$ cases. There was a significant association between reduction of $\mathrm{E}$ cadherin in primary tumours and lymph node metastasis $(P=0.007)$. As well as E-cadherin, the expressions of $\alpha$-catenin and $\beta$-catenin were also significantly reduced in $\mathrm{pN}(+)$ cases as compared with in $\mathrm{pN}(-)$ cases $(P=0.001,<0.001$, respectively).

\section{Association between expression of E-cadherin, $\alpha$-catenin and $\beta$-catenin and features of lymph node metastasis (Table 2)}

We were able to investigate the features of lymph node metastasis, such as the number of metastatic lymph nodes (below two vs over three) and the existence of extracapsular metastatic lymph node in $53 \mathrm{pN}(+)$ cases. We investigated the correlation between the expression of $\mathrm{E}$-cadherin, $\alpha$-catenin and $\beta$-catenin, mode of carcinoma invasion, degree of differentiation, site of the tumour, and tumour size and the features of metastatic lymph node; however, no significant association was recognised.

\section{Association between expression of E-cadherin, $\alpha$-catenin, $\beta$-catenin and clinicopathological features (Table 3)}

The expression of E-cadherin did not appear to differ significantly based on tumour size or the degree of differentiation of the primary tumour. The reduced expression of E-cadherin was found to be related to the grade of carcinoma invasion $(P=0.033)$, meaning that the reduced expression was more frequently found in the tumours with a high grade of mode of carcinoma invasion than in tumours with a low grade of mode of invasion.

The same investigation was performed for $\alpha$-catenin and $\beta$-catenin. There were significant associations between the 

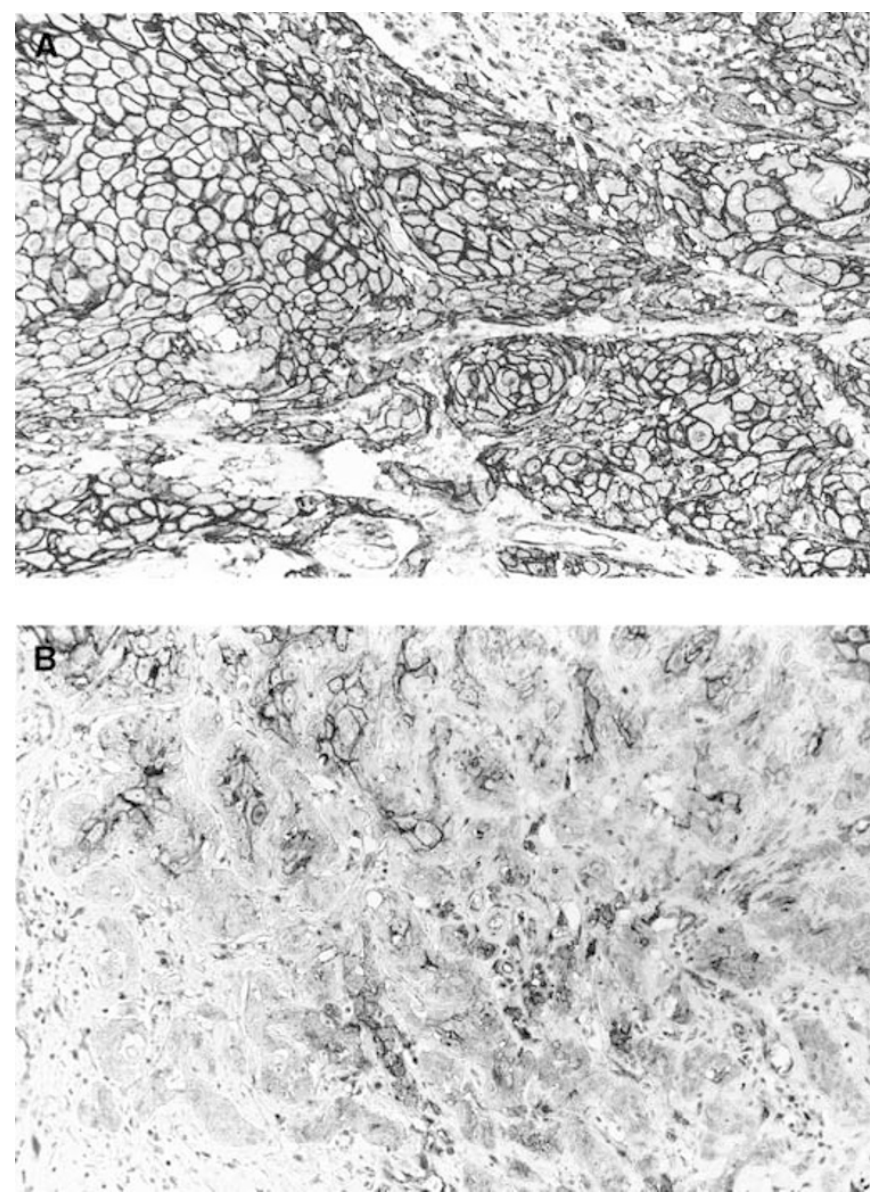

Figure $4 \beta$-catenin expression in oral squamous cell carcinoma. (A) An oral squamous cell carcinoma shows preserved $\beta$-catenin expression, original magnification $\times$ 170; (B) An oral squamous cell carcinoma shows reduced $\beta$-catenin expression, original magnification $\times 170$.

expressions of $\alpha$ - and $\beta$-catenins and the grade of carcinoma invasion of the primary tumour $(P=0.018,0.007$, respectively), meaning that the expressions of $\alpha$-catenin and $\beta$-catenins were reduced in many of the cases with a high grade of mode of carcinoma invasion.

Association between expression of E-cadherin, $\alpha$-catenin, and $\beta$-catenin and survival of patients with oral squamous cell carcinoma (Figure 5)

Survival in patients showing reduced expressions of E-cadherin, $\alpha$ catenin and $\beta$-catenin was significantly shorter than in patients showing preserved expressions $(P=0.0306,0.0033,0.0004$, respectively).

\section{DISCUSSION}

The incidence of neck metastasis in oral squamous cell carcinoma is relatively high (Lee and Krause, 1975, Martis et al, 1979).

The $\mathrm{T}$ classification of oral squamous cell carcinoma was correlated with the incidence of neck metastasis in the current study, which was consistent with the previous reports (Moore et al, 1986a, Mendenhall et al, 1988).

Moore et al (1986b) noted that tumour thickness was an accurate predictor of lymph node metastasis; however, its usefulness might be limited because measurement requires resection of the lesion.
Table I Correlation of regional metastasis and clinicopathological findings in 159 patients with oral squamous cell carcinoma

\begin{tabular}{|c|c|c|c|}
\hline Clinicopathological feature & $\mathbf{p N}(-)$ & $\mathrm{pN}(+)$ & \\
\hline \multicolumn{4}{|l|}{ Age (years) } \\
\hline$<50$ & 18 & 11 & $P=0.914$ \\
\hline $50-69$ & 61 & 44 & $\chi^{2}=0.830$ \\
\hline$>69$ & 16 & 9 & \\
\hline \multicolumn{4}{|l|}{ Gender } \\
\hline Male & 38 & 17 & $P=0.057$ \\
\hline Female & 57 & 47 & $\chi^{2}=0.081$ \\
\hline \multicolumn{4}{|l|}{ Tumour site } \\
\hline Tongue & 56 & 28 & $P=0.058$ \\
\hline Upper gingiva & 6 & I & $\chi^{2}=0.016$ \\
\hline Lower gingiva & 16 & 10 & \\
\hline Floor of mouth & 8 & 19 & \\
\hline Buccal mucosa & 8 & 5 & \\
\hline Lip & । & । & \\
\hline \multicolumn{4}{|l|}{ Tumor size } \\
\hline TI\&T2 & 84 & 43 & $P=0.001$ \\
\hline T3\&T4 & 11 & 21 & $\chi^{2}=0.001$ \\
\hline \multicolumn{4}{|l|}{ Differentiation } \\
\hline Well & 52 & 32 & $P=0.190$ \\
\hline Moderate & 36 & 21 & $\chi^{2}=0.158$ \\
\hline Poor & 7 & 11 & \\
\hline \multicolumn{4}{|l|}{ Mode of invasion } \\
\hline Expansive & 20 & 5 & $P=0.004$ \\
\hline Moderately invasive & 50 & 30 & $\chi^{2}=0.014$ \\
\hline Markedly invasive & 25 & 29 & \\
\hline \multicolumn{4}{|l|}{ E-cadherin } \\
\hline$>75 \%$ & 47 & 20 & $P=0.007$ \\
\hline $25-75 \%$ & 32 & 23 & $\chi^{2}=0.027$ \\
\hline$<25 \%$ & 16 & 21 & \\
\hline \multicolumn{4}{|l|}{$\alpha$-Catenin } \\
\hline$>75 \%$ & 35 & 9 & $P=0.001$ \\
\hline $25-75 \%$ & 37 & 27 & $\chi^{2}=0.003$ \\
\hline$<25 \%$ & 23 & 28 & \\
\hline \multicolumn{4}{|l|}{$\beta$-Catenin } \\
\hline$>75 \%$ & 38 & 7 & $P<0.001$ \\
\hline $25-75 \%$ & 33 & 27 & $\chi^{2}=0.000$ \\
\hline$<25 \%$ & 24 & 30 & \\
\hline Total & 95 & 64 & \\
\hline
\end{tabular}

The current study dealt with 159 oral squamous cell carcinomas, which is the largest series reporting the correlation between the expression of the E-cadherin-associated molecules and the presence of neck metastasis and it showed a significant correlation between them, indicating that the reduced expression of $\mathrm{E}$ cadherin is a key function in the increased incidence of neck metastasis. Bukholm et al (1998) reported that there was no significant difference between the expression of E-cadherin and the presence of regional metastasis in human breast cancer, and it is said that the significance of changes in the E-cadherin complex may vary from tumour to tumour (Kinsella et al, 1993).

In the present study, there was a significant correlation between the expression of $\alpha$-catenin or $\beta$-catenin and the presence of neck metastasis. It is reported that a significant association was seen between reduction in immunoreactivity of at least one of the following proteins: E-cadherin, $\alpha$-catenin, $\beta$-catenin and $\gamma$-catenin and the presence of metastasis in breast carcinoma (Bukholm et al, 1998). Gofuku et al (1999) stated that reduction of $\alpha$-catenin was a 
Table 2 Correlation of clinicopathological findings and features of regional metastasis

\begin{tabular}{|c|c|c|c|c|c|c|}
\hline Clinicopathological feature & \multicolumn{2}{|c|}{ Number of metastatic lymph nodes } & & \multicolumn{2}{|c|}{ Character of metastatic lymph nodes } & \\
\hline \multicolumn{7}{|l|}{ Tumour site } \\
\hline Gingiva & 5 & 5 & & 5 & 5 & \\
\hline Floor of mouth & 7 & 6 & & 5 & 8 & \\
\hline Buccal mucosa & 2 & 1 & & 2 & । & \\
\hline $\mathrm{T} 3$ and T4 & 13 & 9 & & 12 & 10 & \\
\hline \multicolumn{7}{|l|}{ Differentiation } \\
\hline Well & 14 & 10 & $P=0.331$ & 10 & 14 & $P=0.288$ \\
\hline Moderate & 15 & 4 & & 12 & 7 & \\
\hline Poor & 6 & 4 & & । & 9 & \\
\hline \multicolumn{7}{|l|}{ Mode of invasion } \\
\hline \multicolumn{7}{|l|}{ E-cadherin } \\
\hline$>75 \%$ & 8 & 3 & $P=0.633$ & 7 & 4 & $P=0.085$ \\
\hline $25-75 \%$ & 13 & 7 & & 9 & 11 & \\
\hline$<25 \%$ & 14 & 8 & & 7 & 15 & \\
\hline \multicolumn{7}{|l|}{$\alpha$-Catenin } \\
\hline$>75 \%$ & 4 & 2 & $P=0.806$ & 4 & 2 & $P=0.420$ \\
\hline $25-75 \%$ & 17 & 8 & & 10 & 15 & \\
\hline$<25 \%$ & 14 & 8 & & 9 & 13 & \\
\hline \multicolumn{7}{|l|}{$\beta$-Catenin } \\
\hline$>75 \%$ & 2 & I & $P=0.383$ & 2 & 1 & $P=0.559$ \\
\hline $25-75 \%$ & 12 & 9 & & 9 & 12 & \\
\hline
\end{tabular}

Table 3 Correlation of the expression of E-cadherin, $\alpha$-catenin, $\beta$-catenin and clinicopathological findings

\begin{tabular}{|c|c|c|c|c|c|c|c|c|c|c|c|c|}
\hline Clinicopathological feature & \multicolumn{3}{|c|}{ E-cadherin } & & \multicolumn{3}{|c|}{$\alpha$-catenin } & & \multicolumn{3}{|c|}{$\beta$-catenin } & \\
\hline \multicolumn{13}{|l|}{ Tumour size } \\
\hline $\mathrm{T} 3$ and $\mathrm{T} 4$ & 10 & 15 & 7 & $\chi^{2}=0.234$ & 5 & 18 & 9 & $\chi^{2}=0.089$ & 5 & 16 & 11 & $\chi^{2}=0.144$ \\
\hline \multicolumn{13}{|l|}{ Differentiation } \\
\hline Poor & 6 & 5 & 7 & & 5 & 5 & 8 & & 4 & 8 & 6 & \\
\hline \multicolumn{13}{|l|}{ Mode of invasion } \\
\hline Expansive & 15 & 8 & 2 & $P=0.033$ & 10 & 9 & 6 & $P=0.018$ & 12 & 11 & 2 & $P=0.007$ \\
\hline Moderately invasive & 34 & 25 & 21 & $\chi^{2}=0.149$ & 23 & 36 & 21 & $\chi^{2}=0.122$ & 24 & 23 & 33 & $\chi^{2}=0.003$ \\
\hline Markedly invasive & 18 & 22 & 14 & & 11 & 19 & 24 & & 9 & 26 & 19 & \\
\hline
\end{tabular}

more sensitive and useful indicator than the reduction of $\mathrm{E}-$ cadherin in evaluating the potential for tumour invasion and metastasis in human colorectal cancer. However, the mechanism of E-cadherin-mediated intercellular adhesion is not fully understood yet and further study is needed in order to clarify which protein expression among E-cadherin, $\alpha$-catenin, and $\beta$-catenin is most useful for diagnosis and prediction of metastasis and tumour invasion.

We performed a clinical examination of oral squamous cell carcinoma cases which received neck dissection and the results 

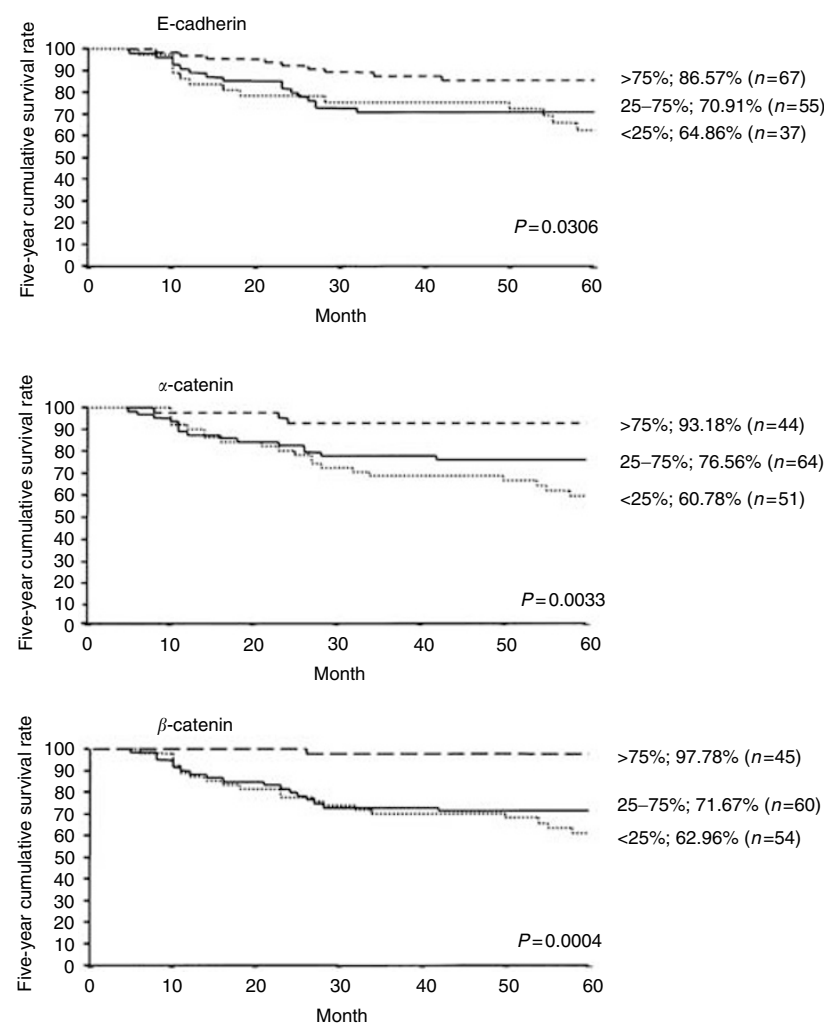

Figure 5 The Five-year cumulative survival rate (Kaplan-Meier). The 5year cumulative survival rate of the patients with reduced expressions of $\mathrm{E}$ cadherin or $\alpha$-catenin or $\beta$-catenin tumours is significantly lower than that with preserved expressions of E-cadherin or $\alpha$-catenin or $\beta$-catenin ones.

indicated that the prognoses of the cases which had three or more metastatic lymph nodes and/or extracapsular metastatic lesion

\section{REFERENCES}

Alberle H, Butz S, Stappert J, Weissig H, Kemler R, Hoschuetzky H (1994) Assembly of the cadherin-catenin complex in vivo with recombinant proteins. J Cell Sci 107: 3655 - 3663

Andrews NA, Jones AS, Helliwell TR, Kinsella AR (1997) Expression of the E-cadherin-catenin cell adhesion complex in primary squamous cell carcinomas of the head and neck and their nodal metastasis. Br J Cancer 75: $1474-1480$

Birchmeier W, Weidner KM, Hulsken J, Behrens J (1993) Molecular mechanisms leading to cell junction (cadherin) deficiency in invasive carcinomas. Semin Cancer Biol 4: 231-239

Bukholm IK, Nesland JN, Karesen R, Jacobsen U, Borresen-Dale AL (1998) E-cadherin and $\alpha$-, $\beta$ - and $\gamma$-catenin protein expression in relation to metastasis in human breast carcinoma. J Pathol 185: 262-266

Gofuku J, Shiozaki H, Tsujinaka T, Inoue M, Tamura S, Doki Y, Matui S, Tsukita S, Kikkawa N, Monden M (1999) Expression of E-cadherin and $\alpha$-catenin in patients with colorectal carcinoma. Correlation with cancer invasion and metastasis. Am J Clin Pathol 111: 29-37

Jones AS, Cook JA, Phillips DE, Roland NJ (1993) Squamous carcinomas presenting as an enlarged cervical lymph node. Cancer 72: $1756-$ 1761

Kadowaki T, Shiozaki H, Inoue M, Tamura S, Oka H, Doki Y, Iihara K, Matsui S, Iwazawa T, Nagafuchi A, Tsukita SO, Mori T (1994) E-cadherin and $\alpha$-catenin expression in human esophageal cancer. Cancer Res 54: 291-296

Kinsella AR, Green B, Lepts GC, Hill CL, Bowie G, Taylor BA (1993) The role of cell adhesion E-cadherin in large bowel tumour cell invasion and metastases. Br J Cancer 67: 904-909

Knusden KA, Soler AP, Johnson KP, Wheelock MJ (1995) Interaction of alpha-actin with the cadherin catenin cell-cell adhesion complex via $\alpha$ catenin. J Cell Biol 130: 67-77 were poor. Therefore, we investigated the correlation between the expression of E-cadherin, $\alpha$-catenin and $\beta$-catenin and the presence of three or more metastatic lymph nodes and/or extracapsular metastatic lesions. However, there were no correlations between them. We reported that from ultrastuctural observation of primary and metastatic oral squamous cell carcinomas, morphologic similarity was recognised between the primary and metastatic lesions; however, the features of junctional complexes varied from the primary lesion to the metastatic one in some cases (Tanaka et al, 2002). Whether regional metastasis occurs or not may depend on the features of the primary lesion, including the intercellular adhesion of the tumour cells. However, the features of the metastatic lesion may be independent of those of the primary lesion and may be mainly influenced by circumustances unique to the metastatic lesion itself.

Mode of carcinoma invasion evaluated from the biopsied specimens has already been reported to be related to regional metastasis (Yamamoto et al, 1984), which is consistent with the result of the current study. Tumour invasion is also related to intercellular adhesion and there were also correlations between the mode of carcinoma invasion and the expressions of E-cadherin, $\alpha$ catenin and $\beta$-catenin.

The $\mathrm{T}$ classification correlated with the presence of neck metastasis, however not with the expression of E-cadherin, $\alpha$ catenin or $\beta$-catenin. Growth of the tumour may correlate not only with intercellular adhesion but also with other factors.

The correlation between mutation or methylation of E-cadherin, $\alpha$-catenin or $\beta$-catenin and the presence of metastasis is now under investigation in order to clarify the mechanism of metastasis (Ogi et al, 2002).

In conclusion, in the cases with oral squamous cell carcinoma that develop regional metastasis, the expression of E-cadherin, $\alpha$ catenin and $\beta$-catenin was reduced and therefore it is strongly suggested that immunohistochemical investigation of these proteins is presently of value for the purpose of diagnosing the presence of metastasis.

Lee JG, Krause CJ (1975) Radical neck dissection: elective therapeutic and secondary. Arch Otolaryngology 101: 656-659

Martis C, Karabouta I, Lazaridis N (1979) Incidence of lymph node metastasis in elective (prophylactic) neck dissection for oral carcinoma. $J$ Oral Maxillofac Surg 7: 182-191

Matsui S, Shiozaki H, Inoue M, Tamura S, Doki Y, Kadowaki T, Iwazawa T, Shimaya K, Nagafuchi A, Tsukita S, Mori T (1994) Immunohistochemical evaluation of alph-catenin expression in human gastric cancer. Virch Arch A 424: 375-381

Mattijssen V, Peters HM, Schalkwijk L, Mann JJ, Hof-Grootenboer BV, DeMulder PHM, Ruiter DJ (1993) E-cadherin expression in head and neck squamous-cell carcinoma is associated with clinical outcome. Int $J$ Cancer 55: $580-585$

McCrea PD, Turck WC, Gumbiner B (1991) A homologue of the armadillo protein in Drosophila (plakogloblin) associated with E-cadherin. Science 254: $1359-1361$

Mendenhall WM, Parsons JT, Million RR (1988) Elective lower irradiation: $500 \mathrm{cGy} / 25$ fractions versus $4050 \mathrm{cGy} / 15$ fractions. Int J Radiat Oncol Biol Phys 15: 439-440

Moore C, Flynn MB, Greenberg RA (1986a) Evaluation of size in prognosis of oral cancer. Cancer 12: $741-746$

Moore C, Kuhns JG, Greenberg RA (1986b) Thickness as prognostic aid in upper aerodigestive tract cancer. Arch Surg 121: 1410-1414

Ochiai A, Akimoto S, Shimoyama Y, Nagafuchi A, Tsukita S, Hirohashi S (1994) Frequent loss of $\alpha$ catenin expression in scirrhous carcinomas with scattered cell growth. Jpn J Cancer Res 85: 266-273

Ogi K, Toyota M, Ohe-Toyota M, Tanaka N, Noguchi M, Sonoda T, Kohama G, Tokino T (2002) Aberrant methylation of multiple genes and clinicopathological features in oral squamous cell carcinoma. Clin Cancer Res 8: $3164-3171$ 
Oyama T, Kanai Y, Ochia A, Akimoto SO, Oda T, Yanagihara K (1994) Truncated $\beta$-catenin disrupts the interaction between E-cadherin and $\alpha$ catenin: a cause of loss of intercellular adhesiveness in human cancer cell lines. Cancer Res 54: 6282-6287

Ozawa M, Kemler R (1992) Molecular organization of the uvomorulincatenin complex. J Cell Biol 116: 989-996

Pierceall WE, Woodard AS, Morrow JS, Rimm D, Fearon ER (1995) Frequent alterations in E-cadherin and $\alpha$-and $\beta$-catenin expression in human breast cancer cell lines. Oncogene 11: 1319-1326

Ponta H, Hoffman, Herrlich P (1994) Recent advances in the genetics of metastasis. Eur J Cancer 13: 1995-2001

Rimm DL, Sinard JH, Morrow JS (1995) Reduced $\alpha$-catenin and E-cadherin expression in breast cancer. Lab Invest 72: 506-512

Sato F, Shimada Y, Watanabe G, Uchida S, Makino T, Imamura M (1999) Expression of vascular endothelial growth factor, matrix metaloproteinase- 9 and E-cadherin in the process of lymph node metastasis in oesophageal cancer. $\mathrm{Br}$ J Cancer 80: 1366-1372

Stappert J, Kemler R (1994) A short core region of E-cadherin is essential for catenin binding and is highly phosphorylated. Cell Adhes Commun 2: $319-327$
Takeichi M (1991) Cadherin cell adhesion receptors as a morphogenetic regulator. Science (Washington DC) 251: $1451-1455$

Tanaka N, Ogi K, Odajima T, Dehari H, Yamada S, Sonoda T, Kohama G (2001) pRb2/p130 protein expression is correlated with clinicopathologic findings in patients with oral squamous cell carcinoma. Cancer 92: $2117-2125$

Tanaka N, Sugihara K, Odajima T, Mimura M, Kimijima Y, Ichinose S (2002) Oral squamous cell carcinoma-Electron microscopic and immunohistochemical characteristics. Med Electron Microsc 35: 127 - 138

Umeda M, Yokoo SO, Take Y, Omori A, Nakanishi K, Shimada K (1992) Lymph node metastasis in squamous cell carcinoma of the oral cavity: correlation between histologic features and the prevalence of metastasis. Head Neck 14: $263-272$

Yamamoto E, Miyakawa A, Kohama G (1984) Mode of invasion and lymph node metastasis in squamous cell carcinoma of the oral cavity. Head Neck 6: $938-947$

Zheng Z, Pan J, Chu B, Wong Y-C, Cheung AL-M, Tsao S-W (1999) Downregulation and abnormal expression of E-cadherin and $\beta$-catenin in nasopharyngeal carcinoma: close association withadvanced disease stage and lymph node metastasis. Hum Pathol 30: 458-466 